\title{
Increased attraction to stranger through neutralization of negative interpersonal affect by repeated evaluation
}

\author{
CHARLES GOUAUX \\ University of Missouri-St. Louis, St. Louis, Mo. 63121
}

The use of a first interpersonal attraction response to neutralize negative affect elicited by the stranger's negative reinforcement of Ss was examined, using three groups. The group which gave two evaluations of the stranger (Group 3) gave significantly more positive second attraction responses than the two control groups: the control group (Group 1) with no time delay between receiving the stranger's dissimilar attitudes and evaluating the stranger $(p<.001)$, and the control group (Group 2) with the same time delay as the experimental group between receiving the stranger's attitudes and evaluating the stranger $(p<.01)$.

Recent research in aggression has given empirical support to a hostility catharsis effect. Berkowitz (1970) suggests that when Ss are rewarded for aggressive behavior and perceive their frustrator being hurt, the Ss experience a "pleasant tension reduction." Berkowitz (1970, p. 6) remarks that regardless of whether we hurt the individual frustrating us or merely perceive the frustrator being hurt or failing in a task, "we evidently feel better."

Within interpersonal attraction research, a similar effect has been noted. Byrne, Lamberth, Palmer, \& London (1969) provided data indicating that Ss' explicit evaluations of strangers somehow neutralize or dissipate the implicit affect elicited by the stranger. This dissipation of affect, according to Byrne et al, accounts for the recency effect they found when attraction responses are interpolated in a sequence of attitudes purportedly given by a stranger. Lamberth, Gouaux, \& Padd (1972) found that Ss indicated a greater reduction in negative affect when they had the opportunity to evaluate the stranger who negatively reinforced them (with negative personal evaluations) than when they did not evaluate the stranger but merely indicated their affective state immediately after receiving negative evaluations from the stranger.

Another important finding in attraction research is the strong positive relationship between attraction and the Ss' affective state (e.g., Gouaux, 1971; Gouaux, Lamberth, \& Friedrich, 1972). That is, more positive attraction responses are associated with more positive affective states in Ss.

The purpose of this study was to attempt to replicate the catharsis effect found by Byrne, Lamberth, Palmer, \& London (1969) and Lamberth, Gouaux, \& Padd (1972), and also to extend the attraction-affect relationship; namely, if Ss negatively reinforced by a stranger indicate a reduction in negative affect after they evaluate the stranger, then these Ss should, if given a second opportunity to evaluate the stranger, give a more positive evaluation of the stranger, since attraction is a positive function of the $S$ 's affective state. It was hypothesized that this second attraction response would be less negative (or more positive) than the first response of comparison groups because of the reduction of negative affect after the first evaluative response.

METHOD
Students in introductory psychology at University of Missouri-St. Louis were administered a 16-item attitude survey at the beginning of the semester. Two months later, $45 \mathrm{Ss}$ were seen in small groups for the experimental session. There were three experimental groups. All Ss first completed a Personal Feelings Scale (PFS), six 7-point semantic differential rating scales (Osgood, Suci, \& Tannenbaum, 1957). The six bipolar items used were sad-happy, pleasant-unpleasant, negative-positive, bad-good, high-low, and comfortable-uncomfortable. Ss then read a "stranger's" 16-item attitude survey. This survey was prepared by the $\mathrm{E}$ to be .15 proportion similar to the S's own attitude survey. Ss then completed the PFS again. Ss in the first group (1) then evaluated the stranger on an Interpersonal Judgment Scale (IJS). The IJS is a six-item 7-point rating scale on which the stranger can be evaluated in terms of his intelligence, knowledge of current events, morality, adjustment, and how much $\mathrm{S}$ would like the stranger and how much $S$ would enjoy working with the stranger. The last two items are summed to yield the dependent measure of attraction ranging from 2 to 14 with a split-half reliability of .85 (Byrne \& Nelson, 1965). These Ss then filled out the PFS for the third time. Ss in the second group (2), after completing the second PFS, filled out a bland information form asking for such information as family data and extracurricular activities on campus. This form took $10-15 \mathrm{~min}$ to complete. Then these Ss again filled out the PFS for the third time, evaluated the stranger on the IJS, and finally completed another PFS. Ss in the third group (3) followed the same procedure as those $S s$ in the second group, except that after completing the second PFS (after receiving the stranger's survey), these Ss evaluated the stranger on a 30-item adjective checklist. The sequence for each group for giving the PFS and IJS responses is shown in Table 1. All Ss were debriefed after they completed the experiment.

\section{RESULTS}

The second PFS scores were compared to the first PFS scores using a one-factor analysis of variance. The second PFS scores were found to be significantly more negative due to the negative reinforcement by the stranger's dissimilar attitudes $(F=18.54, \quad \mathrm{df}=1 / 42, \quad \mathrm{p}<.001)$. Table 1 gives all of the PFS and IJS means and standard deviations for each group.

The catharsis hypothesis was tested by comparing the change scores (third PFS minus second PFS scores) of Groups 1 and 3 with those of Group 2 (which did not give an attraction response between the second and third PFSs). When the change scores were compared between Groups 1 and 2, a significant difference was found $(t=1.82, \mathrm{df}=28, \mathrm{p}<.05)$. When the change scores were compared between Groups 3 and 2 , they also were found to be significantly different $(t=1.89$, $\mathrm{df}=28, \mathrm{p}<.05)$. The change scores for Groups 1 and 3 were not significantly different $(t<1)$. Change scores (fourth PFS minus third PFS) within Groups 2 and 3 were not significant.

A one-factor analysis of variance of the attraction scores for the three groups indicated significant differences among the scores $(F=8.41, \mathrm{df}=2 / 42$, $\mathrm{p}<.001)$. The attraction means for the three groups are shown in Table 1. As predicted, the second attraction or evaluative responses of Group 3 were significantly more positive than the first attraction responses of Group 2 $(\mathrm{t}=2.73, \mathrm{df}=28, \mathrm{p}<.01)$. Moreover, as predicted, the attraction responses of Group 3 were significantly more positive than the responses of Group 1 $(t=5.47, \quad$ df $=28, \quad p<.001)$. The 
Table 1

Means and Standard Deviations of Attraction Scores and the Personal Feelings Scale (PFS) Scores for the Three Groups in Their Respective Time Sequences

\begin{tabular}{|c|c|c|c|c|c|c|}
\hline & \multicolumn{2}{|c|}{ Group 1} & \multicolumn{2}{|c|}{ Group 2} & \multicolumn{2}{|c|}{ Group 3} \\
\hline & Mean & SD & Mean & $\mathrm{SD}$ & Mean & SD \\
\hline First PFS Measure & 29.06 & 7.30 & 30.40 & 7.06 & 30.40 & 7.62 \\
\hline Second PFS Measure & 25.50 & 8.15 & 27.60 & 6.13 & 27.59 & 6.86 \\
\hline Attraction (IJS) & 6.66 & .97 & & & & \\
\hline Third PFS Measure & 28.20 & 7.51 & 28.20 & 6.35 & 31.25 & 6.86 \\
\hline Attraction (IJS) & & & 7.13 & 2.06 & 8.74 & 1.03 \\
\hline Fourth PFS Measure & & & 28.70 & 7.40 & 29.66 & 6.42 \\
\hline
\end{tabular}

attraction means of Groups 1 and 2 did not differ significantly $(t<1)$. DISCUSSION

The catharsis effect noted by Byrne et al and Lamberth et al was found in Group 1 and in Group 3 when each was compared to Group 2. That the change scores, fourth PFS minus third PFS, within Groups 2 and 3 were not significant is probably due to neutralization or dissipation of affect that occurred when the Ss in Groups 2 and 3 completed the information form.

The hypothesis that Ss' second evaluation of the stranger (in Group 3) would be more positive than the Ss' first evaluation in a comparison group (Group 2) having the same general procedure, and in a comparison group (Group 1) not having the same time duration of experimental participation, is supported. Moreover, when Ss evaluated the stranger only once, regardless of the time delay between receiving the stranger's to the Griffitt and Nelson Ss' returning in the second session to their preevaluation affective state of the first session. That is, Ss gave a second attraction response from an affective state similar to that associated with the first attraction response.

\section{REFERENCES}

BER KOWI TZ, L. Experimental investigations of hostility catharsis. Journal of Consulting \& Clinical Psy chology, 1970, 35, 1-7.

BYRNE, D. The attraction paradigm. New York: Academic Press, 1971.

BYRNE, D., LAMBERTH, J., PALMER, J., \& LONDON, $O$. Sequential effects as a function of explicit and implicit interpolated attraction responses. Journal of Personality \& Social Psychology, 1969, $13,70-78$

BYRNE, D., \& NELSON, D. Attraction as a linear function of proportion of positive reinforcements. Journal of Personality \& Social Psychology, 1965, 2, 884-889.

GOUAUX, C. Induced affective states and interpersonal attraction. Journal of Personality \& Social Psychology, 1971, $20,37 \cdot 43$.

GOUAUX, C., LAMBERTH, J., \& FRIEDRICH, G. Affect and interpersonal attraction: A comparison of trait and state measures. Journal of Personality \& Social Psy chology, 1972, in press.

GRIFFITT, W., \& NELSON, P. Short-term temporal stability of interpersonal attraction. Psychonomic Science, 1970, 18. 119-120.

LAMBERTH, J., GOUAUX, C., \& PADD, W. The affective eliciting and reducing properties of attraction stimuli. Unpublished manuscript, University of Oklahoma, 1972.

OSGOOD, C. E., SUCI, G. J., \& TANNENBAUM, P. H. The measurement of meaning. Urbana, III: University of Illinois Press, 1957. 